\title{
Analysis of the Effect of Xi'an Metro Line 2 on Housing Price along the Line on Different Time Points
}

\author{
Yutong Jiao \\ School of Management, XAUAT, Xi'an 710055, China. \\ 513301215@qq.com
}

\begin{abstract}
Urban rail transit is a kind of large public infrastructure with significant economic externality, and its efficient access can improve the house price along significantly. This paper, taking Line 2 of $\mathrm{Xi}$ 'an metro as an example, carries on the regression analysis on the influencing factors of real estate prices on building Hedonic model from regional characteristics, neighborhood characteristics, structure features, and collecting the related data on different time. The empirical results show that the effect of urban rail transit on appreciation of the real estate is different on different time point, and the subway has network effect. Along with the increase in subway lines, the influence of a single line increases gradually.
\end{abstract}

Keywords: Rail transit; Hedonic model; housing price; network effect.

\section{不同时点西安地铁 2 号线对沿线房价的影响分析}

\author{
焦宇肜 \\ 西安建筑科技大学 管理学院, 西安 中国
}

摘 要: 地铁是一种经济外部性显著的大型公共基础设施, 其高效的通达性可以促进沿线周边 住宅价格明显提升。本文以西安地铁2号线为例, 应用特征价格模型分析了仅有2号线一条地 铁线路时, 其沿线6个站点周边的楼盘信息, 发现地铁对周边住宅的影响范围是0-1200m, 房 价平均增值 $3.2 \%$; 1 号线开通后, 进一步分析这6个站点周边房价的变化, 实证结果表明: 这 一时点, 地铁对周边住宅的影响范围扩大到0-1600m, 房价平均增值6.93\%。从而得出地铁具 有网络效应, 随着地铁线路的增多, 单条地铁线路对沿线周边住宅的影响范围和对房价的影 响强度均逐渐变大。

关键词：地铁；特征价格模型；住宅价格；网络效应

1. 前言

我国城市交通拥堵状况随着城市化进程的加快而日渐突出, 轨道交通的建设成为大部分 大中城市解决这一问题的必然选择。城市轨道交通的建设大幅提高了该区域的可达性，推动 了沿线经济的发展与繁荣。根据搜房网、安家网等比较权威的房地产相关网站的数据显示, 西安地铁 2 号线建设以前, 西安市房价价格差异变化不大, 虽然呈上扬趋势, 但上扬缓慢。 地铁 2 号线开始建设以后, 即 2007 年, 城北区房价突然出现 “拐点”, 快速上扬, 以赛高国 际为例, 在 2007 年 8 月到 2008 年 4 月期间, 该街区平均房价上涨 $44.7 \%$, 最高涨幅达到 $65.8 \%$ 。

关于城市轨道交通对沿线房地产价格的影响一直是国外相关领域的研究热点之一。在国 内, 城市轨道交通对住宅价格影响方面的研究起步较晚, 有针对性的研究相对较少, 而且主 要是针对广州、深圳、上海、北京等城市轨道交通的研究。而且综合国内外的研究可以发现, 
国内外学者在研究城市轨道交通对房价的影响时, 无一例外的选择某一城市的某一条线路作 为研究对象, 只分析所选线路对其沿线周边住宅价格的影响, 而本文在此基础之上, 进一步 对比分析单一地铁线路和网络化地铁线路对沿线周边住宅价格影响的不同, 得出地铁线路逐 步网络化对住宅价格的影响范围及影响程度的变化规律。基于本文的研究目的, 相比较北京、 上海、广州这些已经拥有网络化城市轨道交通线路的城市, 选择正处于过渡期的西安作为研 究对象更加符合研究条件。

\section{2. 特征价格模型的构建}

\section{1. 模型形式}

特征价格模型(Hedonic Price Model)是一种分析商品特征价格的计量经济学方法，可以揭 示商品的各个特征对价格的贡献程度。特征价格理论认为房地产价格是由房地产不同的特征 组合所带给消费者的效用决定的, 当房地产自身的特征数量或组合方式发生改变时, 价格也 会随之产生差异。因此, 若使用特征价格模型将影响房地产价格的因素分解, 求出各特征所 隐含的价格, 便可以揭示房地产某一特征对价格的纯粹影响幅度。本文即是应用特征价格模 型, 排除了其他影响因素, 只研究轨道交通对住宅价格的影响。

2.2 特征变量选择

在引用特征价格模型对房地产市场进行研究时，特征变量的选择是十分重要的步骤。综 合分析影响房地产价格的各项属性, 在构建价格模型时, 特征变量可以分为区位特征、邻里 特征以及建筑结构特征三类。特征变量的选择如表1:

表1 特征变量类型

\begin{tabular}{ccc}
\hline 变量类型 & 变量名称 & 变量意义 \\
\hline 区位特征变量 & $d S$ tation & 与最近地铁站点的距离 $(\mathrm{m})$ \\
& $\mathrm{dCBD}$ & 与CBD的最近距离 $(\mathrm{m})$ \\
& $\mathrm{dmBus}$ & 周边公交线路状况, 虚拟变量, 好为 1 , 差为 0 \\
邻里特征变量 & $\mathrm{dmScho}$ & 周边是否有名校, 虚拟变量, 有为 1 , 没有为 0 \\
& $\mathrm{dmShop}$ & 周边是否有超市, 虚拟变量, 有为 1 , 没有为 0 \\
& $\mathrm{dmPark}$ & 周边是否有公园, 虚拟变量, 有为 1 , 没有为 0 \\
结构特征变量 & $\mathrm{dmDeco}$ & 是否精装, 虚拟变量, 是为 1, 不是为 0 \\
& $\mathrm{dmType}$ & 是否高层, 虚拟变量, 是为 1, 不是为 0 \\
\hline
\end{tabular}

\section{3. 样本选择与实证分析}

\section{1. 样本数据的选择}

西安地铁 2 号线为西安地铁首条开工线路, 2006 年 9 月 28 日开工建设, 2011 年 9 月 16 日通车试运营, 全长 $20.50 \mathrm{~km}$, 设车站 17 座。线路北起位于未央区的西安火车北客站, 南至 位于雁塔区的曲江国际会展中心, 将西安南北相连。在地铁 2 号线运营期间, 地铁 1 号线于 2013 年 9 月通车运营, 地铁 3 号线预计 2015 年底通车运营, 地铁 4 号线于 12 年底开工建设。

本文分别选取开盘时间为 2011 年和 2014 年的西安地铁 2 号线所设地铁站: 行政中心、 大明宫西、龙首原、永宁门、南稍门以及会展中心六个站站点周边的 109 个楼盘的住宅均价 作为研究样本。其中, 楼盘单价、类型、装修程度以及三个邻里特征变量主要通过实地调研 和房产网站获得；步行距离和最短行车距离通过电子地图测距而获得。

3.2 模型回归分析

3.2. 1 模型的估计

计量经济学模型的参数估计方法主要分为四类: 最大似然法、最小二乘法、广义矩阵法 和贝叶斯估计法。在多元线性回归分析中经常用到的是最小二乘法。

对于模型 $\left.L n P=\beta_{0}+\sum \beta_{i} x_{i}+\alpha d+\varepsilon （ i=1,2,3 ， \ldots, n\right)$ 而言，最小二乘估计的思想是使得误差项 
$\varepsilon=\operatorname{LnP}-\beta_{0^{-}}-\sum \beta_{\mathrm{i}} \mathrm{x}_{\mathrm{i}}-\alpha \mathrm{d}$

达到最小, 即是要确定模型的参数使得残差平方和

$\sum \varepsilon^{2}=\sum\left(\operatorname{LnP}-\beta_{0}-\beta_{\mathrm{i}} \mathrm{x}_{\mathrm{i}}-\alpha \mathrm{d}\right)^{2}$

尽可能最小。使用式 (3) 对 $\beta_{i}$ 求导, 并使其等于零, 便可求解得到回归模型参数的最小 二乘估计式。

\section{2 .2 结果分析}

通过数据模拟, 发现楼盘到地铁站点的距离为 $1600 \mathrm{~m}$ 时, 达到一个临界状态。所以, 选 择0-1600m这个区间作为研究对象。为了更好的分析出地铁建设对不同距离的房地产价格的影 响程度, 引入虚拟变量 $\mathrm{dm}_{1}-\mathrm{dm} \mathrm{m}_{4}$ 将区间平均分划, 即到地铁站点的距离以 $400 \mathrm{~m}$ 为区间, 用 $\mathrm{dm}_{1}$ 、 $d m_{2} 、 d m_{3} 、 d m_{4} 4$ 个虚拟变量替换 $d$ Station。 $d m_{1}$ 表示楼盘到站点的距离为 $0 m-400 m$, 在该区域 取1, 不在该区域取 $0 ; d m_{2}$ 表示楼盘到站点的距离为 $400 \mathrm{~m}-800 \mathrm{~m}$, 在该区域取 1 , 不在该区域 取0; $d m_{3}$ 表示楼盘到站点的距离为 $800 m-1200 m$, 在该区域取1, 不在该区域取0; dm4表示楼 盘到站点的距离为 $1200 \mathrm{~m}-1600 \mathrm{~m}$ ，在该区域取1，不在该区域取0。

选择回归效果最好的强行进入法对样本数据进行回归分析, 模型回归效果如表 2。

表2 模型统计汇总

\begin{tabular}{ccccc}
\hline 模型 & $R$ & $R$ 方 & 调整 $R$ 方 & 标准估计的误差 \\
\hline 2014 年 & 0.939 & 0.881 & 0.803 & 0.117 \\
2011 年 & 0.947 & 0.895 & 0.830 & 0.086 \\
\hline
\end{tabular}

由表 2 可以看出, 调整后的 $\mathrm{R}^{2}$ 分别为 0.803 和 0.830 , 这说明进入模型的全体自变量总体 上对因变量 LnP 的影响的显著性分别为 $80.3 \%$ 和 $83 \%$, 影响是比较显著的, 模式有较好的总 体解释能力。回归分析同时得出 $\mathrm{F}$ 检验的显著性水平 $\mathrm{t}=0.000$, 说明通过 $\mathrm{F}$ 检验。

表3和表4分别为2014年和2011年样本数据的回归分析系数表。

表 32014 年数据模型的回归系数

\begin{tabular}{|c|c|c|c|c|c|c|}
\hline \multirow[b]{2}{*}{ 模型 } & & \multicolumn{2}{|c|}{ 非标准化系数 } & \multirow{2}{*}{$\frac{\text { 标准系数 }}{\text { Beta }}$} & \multirow[b]{2}{*}{$\mathrm{t}$} & \multirow[b]{2}{*}{ Sig. } \\
\hline & & B & 标准 误差 & & & \\
\hline \multirow[t]{12}{*}{1} & （常量） & 9.003 & .052 & & 174.185 & .000 \\
\hline & $\mathrm{dm} 1$ & .196 & .017 & .556 & 11.823 & .083 \\
\hline & $\mathrm{dm} 2$ & .068 & .013 & .258 & 5.392 & .048 \\
\hline & $\mathrm{dm} 3$ & .066 & .014 & .251 & 5.296 & .000 \\
\hline & $\mathrm{dm} 4$ & .062 & .016 & .221 & 3.843 & .001 \\
\hline & $\mathrm{dCBD}$ & -.042 & .018 & -.112 & -2.265 & .032 \\
\hline & dmBus & .000 & .015 & -.001 & -.024 & .981 \\
\hline & dmScho & .554 & .031 & .744 & 17.927 & .000 \\
\hline & dmShop & .004 & .012 & .016 & .321 & .040 \\
\hline & dmPark & .006 & .012 & .024 & .505 & .618 \\
\hline & dmDeco & .001 & .031 & .002 & .037 & .031 \\
\hline & dmType & -.019 & .018 & -.048 & -1.047 & .304 \\
\hline
\end{tabular}

（显著性 $\operatorname{sig}$ 的值用 $p$ 表示, $p<.05$ 为显著)

从表3可以看出, 11 个自变量中有7个产生显著影响进入模型, 分别是: $d m 2 、 d m 3 、 d m 4 、$ dCBD、dmScho、dmShop、dmDeco。可建立方程模型:

$\mathrm{LnP}=0.068 \mathrm{dm} 2+0.066 \mathrm{dm} 3+0.062 \mathrm{dm} 4-0.042 \mathrm{dCBD}+0.554 \mathrm{dmScho}+0.004 \mathrm{dmShop}+0.001 \mathrm{dmDeco}$ 将之转换成以 $\mathrm{P}$ 为自变量的方程: 


\section{$\mathrm{P}=\mathrm{e}^{0.068 \mathrm{dm} 2+0.066 \mathrm{dm} 3+0.062 \mathrm{dm} 4-0.042 \mathrm{dCBD}+0.554 \mathrm{dmScho+0.004dmShop+0.001dmDeco}}$}

其中, 住宅到 $C B D$ 距离 $\mathrm{dCBD}$ 的系数为负值, 这表明在其它条件不变的情况下, 住宅越靠 近CBD, 平均价格相对越高; dmScho、dmShop的系数为正值, 表明住宅附近的名校、超市越 多, 住宅价格越高; dmDeco的系数为正值, 表明装修程度与住宅价格呈正相关, 即精装修的 住宅价格高于毛坏房的价格。

对于模型中的虚拟变量而言, $d m 2 、 d m 3 、 d m 4$ 三个变量的显著性 $p<0.05$, 说明这些变量对 住宅的价格影响显著, 而 $\mathrm{dm} 1$ 表现不显著, 这表示住宅距离地铁站点 $0-400 \mathrm{~m}$ 范围内, 住宅到 地铁站点的距离对住宅价格的影响效果并不明显, 可能是由于地铁站点附近的人流密集, 噪 音污染、社会治安等问题对住宅价格产生的负向影响大于了轨道交通可达性的正向影响。

表 42011 年数据模型的回归系数

\begin{tabular}{|c|c|c|c|c|c|c|}
\hline \multirow[b]{2}{*}{ 模型 } & & \multicolumn{2}{|c|}{ 非标准化系数 } & \multirow{2}{*}{$\frac{\text { 标准系数 }}{\text { Beta }}$} & \multirow[b]{2}{*}{$\mathrm{t}$} & \multirow[b]{2}{*}{ Sig. } \\
\hline & & B & 标准 误差 & & & \\
\hline \multirow[t]{12}{*}{1} & (常量) & 12.073 & .272 & & 74.522 & .000 \\
\hline & $\mathrm{dm} 1$ & .071 & .047 & .156 & 7.873 & .013 \\
\hline & $\mathrm{dm} 2$ & .036 & .073 & .108 & 5.482 & .037 \\
\hline & $\mathrm{dm} 3$ & .027 & .044 & .051 & 5.241 & .049 \\
\hline & $\mathrm{dm} 4$ & .012 & .056 & .021 & 2.713 & .461 \\
\hline & $\mathrm{dCBD}$ & -.031 & .003 & -.132 & -2.143 & .030 \\
\hline & dmBus & .000 & .002 & -.071 & -.033 & .892 \\
\hline & dmScho & .026 & .052 & .078 & .746 & .421 \\
\hline & dmShop & .024 & .030 & .076 & 2.904 & .023 \\
\hline & dmPark & .026 & .053 & .069 & .569 & .574 \\
\hline & dmDeco & .011 & .071 & .013 & .434 & .231 \\
\hline & dmType & -.016 & .051 & -.031 & -2.987 & .004 \\
\hline
\end{tabular}

从表4可以看出，11个自变量中有6个产生显著影响进入模型，分别是： $\mathrm{dm} 1 、 \mathrm{dm} 2 、 \mathrm{dm} 3 、$ $d C B D 、 d m S h o p 、 d m T y p e$ 。可建立以 $P$ 为自变量的方程:

$\mathrm{P}=\mathrm{e}^{0.071 \mathrm{dm} 1+0.036 \mathrm{dm} 2+0.027 \mathrm{dm} 3-0.031 \mathrm{dCBD}+0.024 \mathrm{dm} \text { Shop-0.016dmType }}$

对于模型中的虚拟变量而言, $d m 1 、 d m 2 、 d m 3$ 三个变量的显著性 $p<0.05$, 并且 $p$ 值逐渐 增大, 说明当住宅距离站点 $1200 \mathrm{~m}$ 范围内时, 地铁对周边的住宅价格影响是显著的, 但是这 种影响的显著性随着站点到住宅距离的增加而呈下降趋势。 $d m 4$ 所对应的显著性 $p=0.461>$ 0.05 , 说明当住宅到站点的距离大于 $1200 \mathrm{~m}$ 时，地铁对周边的住宅价格影响不显著。

从上述分析中对比发现，单一地铁线路和趋于网络化的地铁线路对沿线住宅的影响范围 是不同的, 地铁线路网络化之后对沿线住宅的影响范围更大。即随着城市轨道交通线路的增 多, 地铁线路的影响范围逐渐变大。

3.3 地铁的增值效果分析

根据表 3 , 三个显著性 $\mathrm{p}<0.05$ 的虚拟变量 $\mathrm{dm}_{2} 、 \mathrm{dm}_{3} 、 \mathrm{dm}_{4}$ 对应的住宅单价对数的比值: $\mathrm{LnP}_{2}: \mathrm{LnP}_{3}: \mathrm{LnP}_{4}=0.068: 0.066: 0.062$, 即住宅到地铁站点的距离在 $400 \mathrm{~m}-800 \mathrm{~m} 、 800 \mathrm{~m}-1200 \mathrm{~m}$ 、 $1200 \mathrm{~m}-1600 \mathrm{~m}$ 时的住宅单价比分别为: $P_{2}: P_{3}: P_{4}=e^{0.068}: e^{0.066}: e^{0.062}=1.0703: 1.0682: 1.0639$ 。 由此可见, 地铁建设对其周边 $1600 \mathrm{~m}$ 范围内的住宅价格的影响为: 住宅价格在 $400 \mathrm{~m}-800 \mathrm{~m}$ 范 围内增值最明显, 该区域内与该区域之外相比住宅增值7.03\%; 范围在 $800 \mathrm{~m}-1200 \mathrm{~m}$ 时, 区域 内住宅相比区域外住宅单价上升6.82\%; 范围在 $1200 \mathrm{~m}-1600 \mathrm{~m}$ 时, 区域内住宅相比区域外住宅 单价上升 $6.39 \%$ 。平均每靠近地铁站点 $100 \mathrm{~m}$ ，住宅单价增值 $1.3 \%$ 。

根据表4分析, 三个显著性 $\mathrm{p}<0.05$ 的虚拟变量 $\mathrm{dm}_{1} 、 \mathrm{dm}_{2} 、 \mathrm{dm}_{3}$ 对应的住宅单价比分别为: $P_{1}$ ： $P_{2}$ ： $P_{3}=1.0736$ : 1.0366: 1.0274。由此得出：地铁建设对其周边1600m范围内的住宅价格 
的影响为：范围在 $400 \mathrm{~m}$ 内时，增值效果最明显，区域内住宅相比区域外住宅单价上升 $7.36 \%$ 。 在 $400 \mathrm{~m}-800 \mathrm{~m}$ 范围内, 区域内与该区域之外相比住宅增值 $3.66 \%$; 范围在 $800 \mathrm{~m}-1200 \mathrm{~m}$ 时, 区 域内住宅相比区域外住宅单价上升 $2.74 \%$ 。平均每靠近地铁站点 $100 \mathrm{~m}$ ，住宅单价增值 $0.86 \%$ 。

对比 2011 年和 2014 年地铁的增值效果，可以发现：单一地铁线路和趋于网络化的地铁 线路对沿线住宅价格的影响程度是不同的，地铁线路网络化之后对沿线住宅价格的影响程度 更大。随着城市轨道交通线路的增多，地铁对沿线周边住宅价格的影响程度越来越大。

\section{4. 结论}

经过综合比较选择回归效果最好的半对数模型，从区位特征、邻里特征和结构特征三个 方面建立了地铁沿线房价与影响因素之间的特征价格模型, 并搜集了不同时点西安地铁 2 号线 周边住宅的相关数据, 定量分析了地铁建设对其周边住宅价格的影响。再进一步对单一地铁 线路和网络化地铁线路进行对比分析, 实证结果表明地铁具有网络效应, 在不同的时点, 地 铁建设对其沿线住宅价格的影响也有很大的不同。

（1）地铁建设对其沿线住宅的影响范围。对比两组数据的回归分析结果，可以发现：仅 有一条城市轨道交通线路开通时（2011年），地铁沿线周边1200m范围内住宅的价格受到显 著影响, 且距离站点越近, 对价格的影响越大。随着城市轨道交通线路增加（2014年）, 地 铁的影响范围逐渐向外扩张, 距离站点400-1600m范围内的住宅价格受到显著影响, 即轨道交 通线路的增加, 使地铁的影响范围从0-1200m扩大到0-1600m。由此可见, 单一地铁线路和趋 于网络化的地铁线路对沿线住宅的影响范围是不同的, 地铁线路网络化之后对沿线住宅的影 响范围更大。

（2）地铁建设对其沿线住宅价格的影响程度。对比2011年和2014年两组样本数据的地铁 增值效果分析, 可以发现: 在 $400 \mathrm{~m}-1200 \mathrm{~m}$ 范围内, 不同时点地铁对住宅价格都有显著的影响, 可是影响的程度却大有不同。仅有一条城市轨道交通线路开通时（2011年），由于地铁这一 因素的影响，在400m-1200m范围内的住宅平均增值3.2\%; 随着城市轨道交通线路增加（2014 年）, 在 $400 \mathrm{~m}-1200 \mathrm{~m}$ 范围内的住宅平均增值 $6.93 \%$ 。这说明不同时点地铁建设对沿线房价的 影响程度是不同的, 地铁线路逐步网络化后对周边住宅价格的影响程度远远高于单一地铁线 路对住宅价格的影响程度。

\section{References}

[1] Allen W, Boyce D. Impact of high - speed transit facility of residential property values High Speed Ground Transportation, 1974, 53-60.

[2] ROSEN S. Hedonic Prices and Implicit Markets: Product Differentiation in Pure Competition[J]. Journal of Political Economy, 1974, 34-55.

[3] Knaap G J, Ding C, Hopkins L D. Do plans matter? The effects of light rail plans on la values in station areas-Journal of Planning Education and Research, 2001, 21 (1):32-39.

[4] Han B R1Neighborhood land value changes from subway construction: Case study generalized least squares1Dankook University Regional Studies, 1991, 11:125-1461

[5] 封志明, 刘东, 杨艳昭.中国交通通达度评价:从分县到分省.地理研究, 2009, 28(2) :419-429.

[6] 苏亦宁, 冯长春. 城市轨道交通对其沿线住宅价格的分析一一以北京市地铁四号线和八通 线为例 $[\mathrm{J}]$. 城市住房，2011，18（7）：108-113.

[7] 聂冲, 温海珍, 樊晓锋. 城市轨道交通对房地产增值的时空效应 [ J ] . 地理研究, 2010, 29 (5) : 801-810. 